\title{
Origin and Distribution of PAHs in Ambient Particulate Samples at High Mountain Region in Southern China
}

\author{
Peng-hui Li, ${ }^{1}$ Yan Wang, ${ }^{2}$ Yu-hua Li, ${ }^{3}$ Hong-li Li, ${ }^{3}$ and Xianliang $\mathrm{Yi}^{4,5}$ \\ ${ }^{1}$ School of Environmental Science and Safety Engineering, Tianjin University of Technology, Tianjin 300384, China \\ ${ }^{2}$ School of Environmental Science and Engineering, Shandong University, Jinan 250100, China \\ ${ }^{3}$ Shandong Environmental Monitoring Center, Jinan 250101, China \\ ${ }^{4}$ The Swire Institute of Marine Science, The University of Hong Kong, Pokfulam, Hong Kong \\ ${ }^{5}$ State Key Laboratory of Environmental Criteria and Risk Assessment, Chinese Research Academy of Environmental Sciences, \\ Beijing 100012, China \\ Correspondence should be addressed to Peng-hui Li; lipenghui406@163.com and Yan Wang; wy@sdu.edu.cn
}

Received 6 June 2014; Revised 21 November 2014; Accepted 21 November 2014

Academic Editor: Hesham El-Askary

Copyright ( 2015 Peng-hui Li et al. This is an open access article distributed under the Creative Commons Attribution License, which permits unrestricted use, distribution, and reproduction in any medium, provided the original work is properly cited.

\begin{abstract}
To understand the deposition and transport of PAHs in southern China, a measurement campaign was conducted at a highelevation site (the summit of Mount Heng, $1269 \mathrm{~m}$ A.S.L.) from April 4 to May 31, 2009, and a total of 39 total suspended particulate samples were collected for measurement of PAH concentrations. The observed particulate-bound PAHs concentrations ranged from 1.63 to $29.83 \mathrm{ng} / \mathrm{m}^{3}$, with a mean concentration of $6.03 \mathrm{ng} / \mathrm{m}^{3}$. BbF, FLA, and PYR were the predominant compounds. Good correlations were found between individual PAHs and meteorological parameters such as atmospheric pressure, relative humidity, and ambient temperature. The backward trajectory analysis suggested that particulate samples measured at the Mount Heng region were predominantly associated with the air masses from southern China, while the air masses transported over northern and northwestern China had relative higher PAHs concentrations. Based on the diagnostic ratios and factor analysis, vehicular emission, coal combustion, industry emission, and unburned fossil fuels were suggested to be the PAHs sources at Mount Heng site. However, the reactivity and degradation of individual PAHs could influence the results of PAH source profiles, which deserves further investigations in the future.
\end{abstract}

\section{Introduction}

Polycyclic aromatic hydrocarbons (PAHs) are a group of widespread environmental contaminants, originating from both natural (e.g., forest fires and volcanoes) and anthropogenic sources (e.g., incomplete combustion and pyrolysis of fossil fuels or organic materials). Between the two sources, human activities (i.e., anthropogenic sources) contribute the most to PAHs emissions. This is particularly the case in urban area or industrial areas, where the PAHs sources can be entirely anthropogenic [1-4]. PAHs are persistent and accumulative in environment, and they can cause carcinogenic and mutagenic effects to living things. Thus, these compounds have received more and more attention by environmental scientists for the last several decades. The emission abatement of PAHs has been listed on the agenda of international convention processes, such as the 1979 Geneva Convention on Long-Range Transboundary Air Pollution. Since 1990, reduction of PAHs emission has been reported in U.S. and European countries. In contrast to those developed countries, the PAH emissions in China have been continuously increasing due to the rapid industrialization and economic development [5-7]. The total PAH emission in China was estimated to be about 25,300 tons in the year of 2003 and the major sources were suggested to be domestic coal combustion, biofuel burning, and industry emission [5].

Once released into the atmosphere, PAHs can partition between vapor and particle phases, which is dependent on temperature and vapor pressure of the chemicals $[8,9]$. PAHs with high molecular weight (4-6 rings) tend to be associated with particle phase, while those with lower molecular weight (2-3 rings) are often concentrated in the vapor phase 


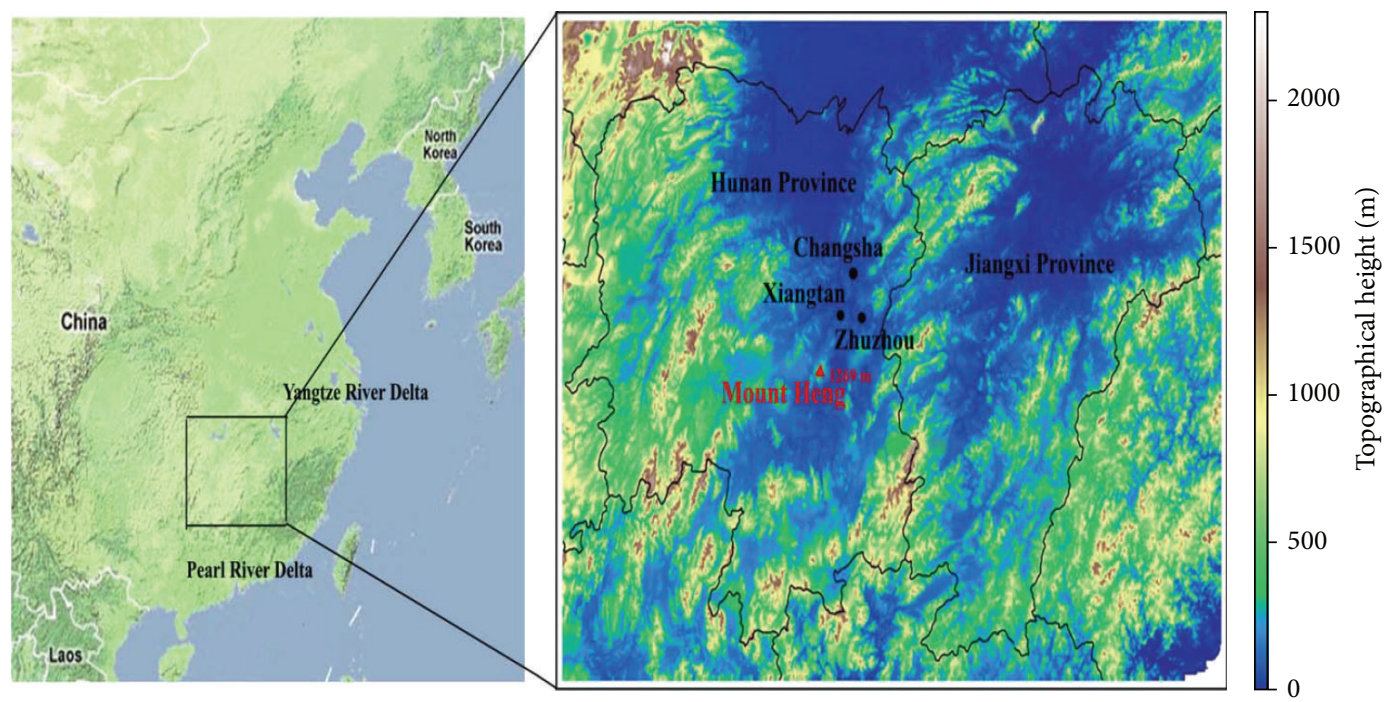

FIGURE 1: Geographical location of Mount Heng (cited from [36]).

[10]. During the course of their transport, PAHs could be removed from the atmosphere due to precipitation and/or dry deposition. Through the grasshopper effect, PAHs can be transported to very long ranges from their original sources [11].

Although a considerable number of studies have been conducted on measurements of PAHs in urban environment, little work has been done in rural sites. Remote mountain regions, particularly with altitude in the free troposphere, are the unique environments for the study of atmospheric pollution load over continental areas, and the study at remote mountain regions can help to get full assessment of the role of the atmosphere in the global distribution of PAHs [12, 13]. In this study, atmospheric particulate samples were collected at the summit of Mt. Heng, which is in the transition region between the free troposphere and boundary layer, and serve as a regionally representative site for studying the long-range transport of pollutants in Southern China. The objectives of the present study were (1) to gain a primary understanding on the distribution of particulate-bound PAHs at Mt. Heng and (2) to examine the possible sources and transport patterns of PAHs in the region.

\section{Materials and Methods}

2.1. Site Description and Sample Collection. The Mount Heng is located in Hunan Province, south China, and it is between two major polluted industrial/urban areas-the Pearl River and Yangtze River deltas. There are two big cities, Shanghai and Guangzhou, situated $900 \mathrm{~km}$ to the east and $400 \mathrm{~km}$ to the south of the Mount Heng, respectively. The sampling site was located at a meteorological station $\left(27^{\circ} 18^{\prime} \mathrm{N}, 112^{\circ} 42^{\prime} \mathrm{E}\right)$, which was set up in the 1937 at the summit of Mount Heng (1269 m A.S.L.) (Figure 1).

The sampling period was carried out from April 4 to May 31, 2009. Total suspended particulate (TSP) samples were collected on glass fibre filters by a middle-volume air sampler (KC-300, Qingdao Laoshan Electronic Instrument Company) daily (22 hours, from 10 a.m. to 8 a.m.). The sampler was operated at a flow rate of $225 \mathrm{~L} / \mathrm{min}$ and a total of 39 TSP samples were collected. Prior to sampling, all the glass fibre filters were combusted at $450^{\circ} \mathrm{C}$ in an oven for $6 \mathrm{~h}$ to volatilize any organic contaminants. After sampling, the glass fibre filters were wrapped in aluminum foils and frozen at $-20^{\circ} \mathrm{C}$, and PAHs analysis was then conducted within two weeks after sampling.

2.2. Sample Preparation and Analysis. The glass fibre filters were extracted by Accelerated Solvent Extractor (Dionex ASE 300) with acetone/ $n$-hexane $(1: 1, \mathrm{v} / \mathrm{v})$ solvents, and the elute was purified using silica gel columns and condensed to exactly $1 \mathrm{~mL}$ with rotary evaporation and nitrogen stream technique. PAHs were then determined using gas chromatography coupled to mass spectrometry (Shimadzu 2010 plus). The details of the extraction and analysis procedure were described elsewhere [1]. Fifteen individual PAHs were detected in this study (Table 1).

2.3. Quality Control. Deuterated perylene-d12 was spiked to all the samples to monitor procedural performance. The mean recoveries based on surrogates in samples were $98.4 \pm$ $6.4 \%$.

Field and method blanks were analyzed using the same procedure as particulate samples, and all the PAHs concentrations were corrected for blanks. The control calibration standards were measured regularly to ensure the performance of instrument during sample analysis.

\section{Results and Discussion}

3.1. Concentrations of PAHs in Particulate Samples. Descriptive statistics for all valid observations of PAHs concentrations in particulate samples collected at Mount Heng are summarized in Table 2. The concentrations of PAHs varied 
TABLE 1: The abbreviations for PAH compounds and their detection limits.

\begin{tabular}{lcc}
\hline PAHs & Abbreviation & Detection limit (ng) \\
\hline Acenaphthylene & ACY & 4 \\
Acenaphthene & ACE & 5 \\
Fluorene & FLU & 5 \\
Phenanthrene & PHE & 3 \\
Anthracene & ANT & 4 \\
Fluoranthene & FLA & 7 \\
Pyrene & PYR & 4 \\
Benz[a]anthracene & BaA & 2 \\
Chrysene & CHR & 7 \\
Benzo[b]fluoranthene & BbF & 3 \\
Benzo[k]fluoranthene & BkF & 4 \\
Benzo[a]pyrene & BaP & 4 \\
Dibenz[a,h]anthracene & DahA & 6 \\
Benzo[g,h,i]perylene & BghiP & 4 \\
Indeno[1,2,3-cd]pyrene & IcdP & 5 \\
\hline
\end{tabular}

from 1.63 to $29.83 \mathrm{ng} / \mathrm{m}^{3}$, with a mean concentration of $6.03 \mathrm{ng} / \mathrm{m}^{3}$. BbF was the predominant compound, with a mean concentration of $0.86 \mathrm{ng} / \mathrm{m}^{3}$, contributing to $14.26 \%$ of the total PAH concentration. FLA, PHE, and PYR comprised the second tier of dominant compounds, with mean concentrations of $0.77,0.74$, and $0.60 \mathrm{ng} / \mathrm{m}^{3}$, respectively. Similar distribution of individual PAHs has been reported in previous studies in China. For the research done by our group at the Mount Tai (the highest mountain at northern China, $1534 \mathrm{~m}$ A.S.L.), BbF, FLA, and PYR were the most abundant PAH compounds in $\mathrm{PM}_{2.5}$ samples, accounting for $23.55 \%, 14.21 \%$, and $10.39 \%$ of the total PAH concentration, respectively [1]. Wang et al. [14] also suggested that $\mathrm{BbF}$ was the predominant compound of PAHs in $\mathrm{PM}_{10}$ samples in Beijing. In 2012, China Environmental Protection Agency has published the latest ambient air quality standards, in which the $\mathrm{BaP}$ daily and annual concentration limits were set at $2.5 \mathrm{ng} / \mathrm{m}^{3}$ and $1.0 \mathrm{ng} / \mathrm{m}^{3}$, respectively. The $\mathrm{BaP}$ concentration found in this study met the standard. Together with $\mathrm{BaP}$, several other $\mathrm{PAHs}$ compounds, including BaA, BbF, BkF, IcdP, and DahA, were suggested as potential carcinogenic compounds by the International Agency for Research on Cancer (IARC). The total concentration of these six compounds was $2.30 \mathrm{ng} / \mathrm{m}^{3}$, accounting for $38.14 \%$ of the total PAHs.

The observed PAHs concentrations at the Mount Heng are comparable with our previous studies done at the Mount Tai (fine particles, $6.88 \mathrm{ng} / \mathrm{m}^{3}$; Table 3) [1]. When comparing with other areas, the PAHs concentrations at Mount Heng are much lower than the results reported in urban cities or areas in China, including Beijing [14], Guangzhou [15], and Northern Plain [16]. In contrast, the PAHs concentrations at Mount Heng were higher than the observed concentrations at Waliguan (a global standard observation site, $3810 \mathrm{~m}$ A.S.L., $2.08 \mathrm{ng} / \mathrm{m}^{3}$ ) [17], high mountain regions of Europe $\left(0.07-1.10 \mathrm{ng} / \mathrm{m}^{3}, 2240-2413 \mathrm{~m}\right)$ [18], Mt. Bachelor Observatory (MBO, $<6 \mathrm{ng} / \mathrm{m}^{3}, 2763 \mathrm{~m}$ ) [19], Far East Asia
TABLE 2: Statistical description of PAH concentrations in particulate samples at Mount Heng.

\begin{tabular}{lccc}
\hline \multirow{2}{*}{ Species } & \multicolumn{3}{c}{ PAHs concentrations $\left(\mathrm{ng} / \mathrm{m}^{3}\right)$} \\
\hline ACY & Nd-0.11 & Mean & SD \\
ACE & Nd-0.56 & 0.02 & 0.03 \\
FLU & Nd-0.85 & 0.22 & 0.15 \\
PHE & $0.17-2.83$ & 0.74 & 0.23 \\
ANT & Nd-0.41 & 0.12 & 0.71 \\
FLA & $0.15-4.88$ & 0.77 & 0.12 \\
PYR & $0.13-3.62$ & 0.60 & 0.97 \\
BaA & $0.05-1.68$ & 0.27 & 0.72 \\
CHR & Nd-3.80 & 0.52 & 0.33 \\
BbF & Nd-4.24 & 0.86 & 0.80 \\
BkF & $0.11-1.25$ & 0.36 & 0.88 \\
BaP & $0.08-1.47$ & 0.35 & 0.30 \\
IcdP & Nd-1.80 & 0.39 & 0.31 \\
DahA & Nd-0.53 & 0.07 & 0.39 \\
BghiP & $0.21-2.60$ & 0.64 & 0.11 \\
PAHs & $1.63-29.83$ & 6.03 & 0.51 \\
\hline
\end{tabular}

$\left(0.32 \mathrm{ng} / \mathrm{m}^{3}\right)$, North Pacific Ocean $\left(0.14 \mathrm{ng} / \mathrm{m}^{3}\right)$, and the Arctic area $\left(0.48 \mathrm{ng} / \mathrm{m}^{3}\right)[20]$.

3.2. Correlations of Particulate-Bound PAH Levels with Meteorological Parameters. The meteorological conditions are important factors that can affect the deposition levels of pollutants [21-23]. In the present study, meteorological parameters including atmospheric pressure (press.), relative humidity $(\mathrm{RH})$, and ambient temperature $(T)$ were measured during the sampling period. The correlation coefficients between these meteorological parameters and particulatebound PAHs were analyzed (Table 4). Good correlation was found between atmospheric pressure and several individual PAHs including BkF, BaP, IcdP, and BghiP, suggesting that high atmospheric pressure enhanced the bound of these compounds to the particulate phase. In the study of Tian et al. [21], significant negative correlation was observed between particulate-bound PAHs and ambient temperature, suggesting the temperature dependence for PAHs. Some other studies also highlighted the important role of temperature in PAHs partitioning between gas and particulate phase $[24,25]$. However, in this present study, only five individual PAH compounds including ACY, ACE, BkF, IcdP, and BghiP presented significant negative correlation with temperature. In addition, ACE and FLU had good positive relationships with $\mathrm{RH}$, indicating their $\mathrm{RH}$ dependence.

\subsection{Transport Pattern and Sources of Particulate-Bound} $P A H s$. In previous studies, atmospheric samples always have higher deposition concentrations when they came from the more polluted area $[2,10]$. Back trajectory analysis was conducted in this study to characterize the particulate deposition character influenced by different source regions. 
TABLE 3: Comparison of particulate-bound PAH levels between Mount Heng and other studies.

\begin{tabular}{|c|c|c|c|c|c|}
\hline Sampling site & Sample type & Altitude (m A.S.L.) & $\sum$ PAHs & PAHs concentrations $\left(\mathrm{ng} / \mathrm{m}^{3}\right)$ & Reference \\
\hline Mount Heng, China & TSP & $1269 \mathrm{~m}$ & $\sum 15$ & 6.03 & This research \\
\hline Mount Tai, China & $\mathrm{PM}_{2.5}$ & $1534 \mathrm{~m}$ & $\sum 15$ & 6.88 & [1] \\
\hline Waliguan, China & TSP & $3810 \mathrm{~m}$ & $\sum 14$ & 2.08 & {$[17]$} \\
\hline High Mountain Regions, Europe & TSP & $2240 m-2413 m$ & $\sum 20$ & $0.07-1.10$ & {$[18]$} \\
\hline MBO, US & TSP & $2763 \mathrm{~m}$ & $\sum 14$ & $<4$ & [19] \\
\hline Far East Asia & TSP & NA & $\sum 15$ & 0.32 & {$[20]$} \\
\hline North Pacific Ocean & TSP & NA & $\sum 15$ & 0.14 & {$[20]$} \\
\hline Arctic & TSP & NA & $\sum 15$ & 0.48 & {$[20]$} \\
\hline Beijing, China & $\mathrm{PM}_{10}$ & NA & $\sum 15$ & 44.9 & {$[14]$} \\
\hline Northern Plain, China & TSP & NA & $\sum 16$ & 346 & {$[16]$} \\
\hline Guangzhou, China & TSP & NA & $\sum 16$ & 19.5 & [15] \\
\hline
\end{tabular}

TABLE 4: The correlation coefficients between particulate boundPAH concentrations and meteorological parameters.

\begin{tabular}{lccc}
\hline & Press. $(\mathrm{Pa})$ & $T\left({ }^{\circ} \mathrm{C}\right)$ & $\mathrm{RH}(\%)$ \\
\hline PAHs & 0.627 & -0.639 & 0.226 \\
ACY & 0.551 & $-0.764^{*}$ & 0.665 \\
ACE & -0.025 & -0.234 & $0.940^{* *}$ \\
FLU & -0.078 & -0.166 & $0.938^{* *}$ \\
PHE & 0.389 & -0.554 & 0.700 \\
ANT & 0.472 & -0.641 & 0.621 \\
FLA & 0.541 & -0.571 & 0.119 \\
PYR & 0.555 & -0.564 & 0.076 \\
BaA & 0.572 & -0.537 & 0.050 \\
CHR & 0.531 & -0.475 & 0.015 \\
BbF & 0.688 & -0.644 & 0.174 \\
BkF & $0.733^{*}$ & $-0.718^{*}$ & 0.233 \\
BaP & $0.722^{*}$ & -0.706 & 0.221 \\
IcdP & $0.767^{*}$ & $-0.783^{*}$ & 0.336 \\
DahA & 0.626 & -0.656 & 0.363 \\
BghiP & $0.751^{*}$ & $-0.784^{*}$ & 0.310 \\
\hline
\end{tabular}

Significance level: ${ }^{*} P<0.05,{ }^{* *} P<0.01$.

Forty-eight-hour backward trajectories were calculated using the HYSPLIT (hybrid single-particle Lagrangian integrated trajectory) model at a height of $1269 \mathrm{~m}$ A.S.L.

Based on the analysis, four major trajectory categories were classified for the samples: N/NW, continental air masses from northern and northwestern China, the most polluted region of China; EA, air masses from eastern China, where Shanghai and its surrounding cities located here; $\mathrm{S}$, air masses from the Southern China, transported through the Pearl River Delta region; and L, samples with looped and short trajectories that stayed within a radius of $500 \mathrm{~km}$ of sampling site (Figure 2).

Among the four classified trajectory categories, $\mathrm{S}$ happened most frequently, accounting for $42.9 \%$ of the total, followed by N/NW (37.1\%), EA (14.3\%), and L (5.7\%). As presented in Figure 3, the order of PAHs concentrations among the trajectory categories was N/NW, L, EA, and S.

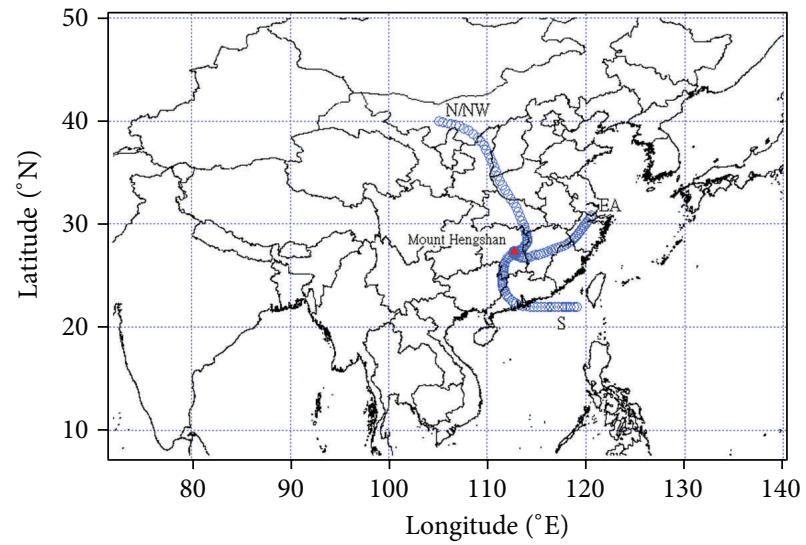

FIGURE 2: Classified pathway of each trajectory category.

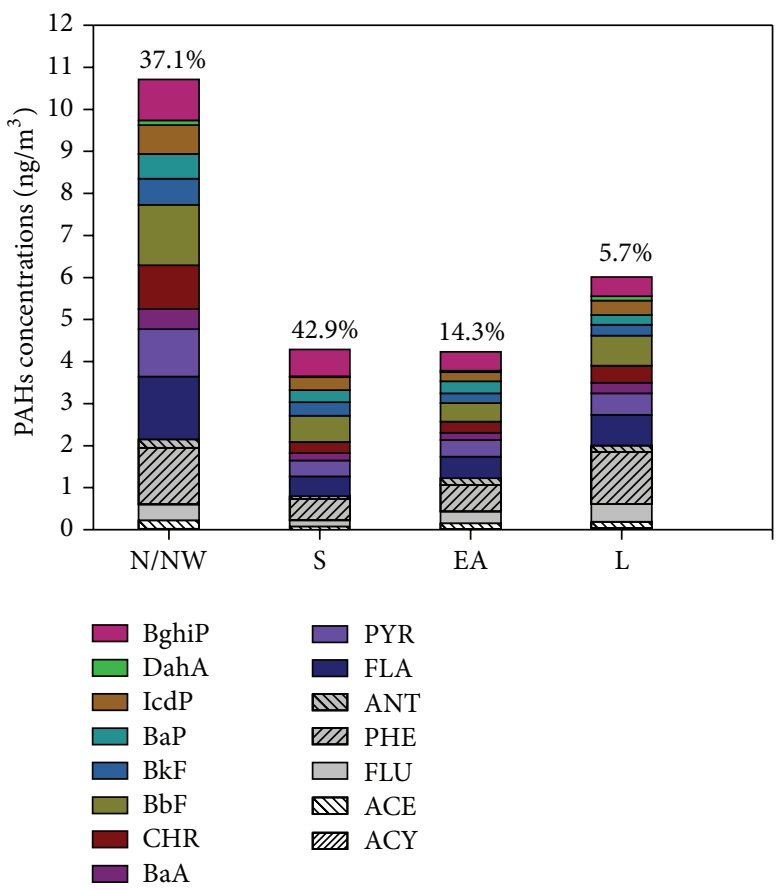

FIGURE 3: PAHs concentrations based on different trajectory categories. 


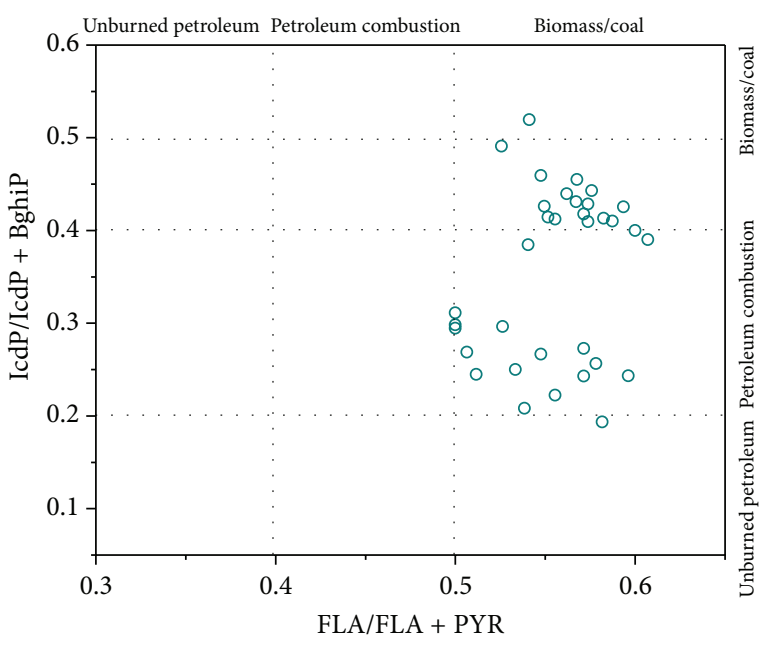

$\circ$ TSP

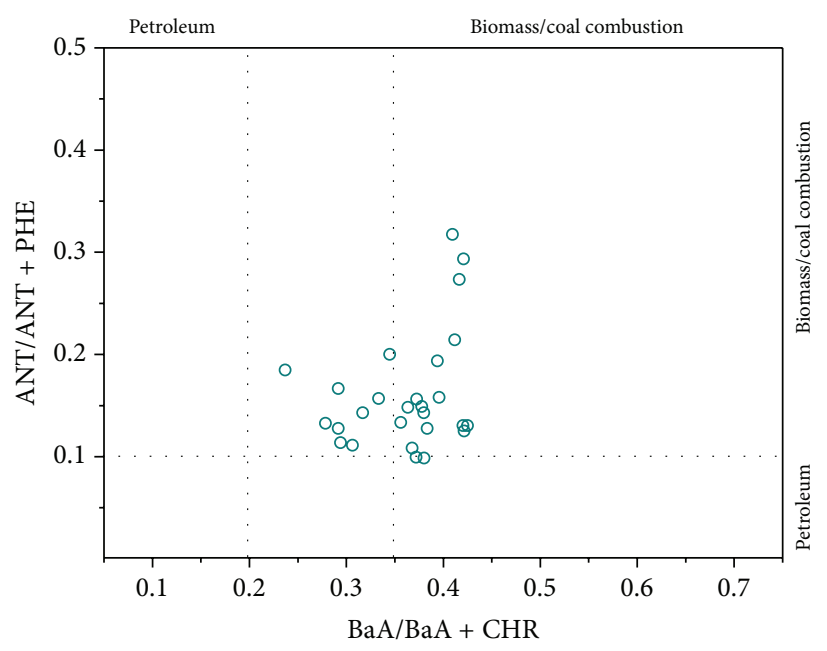

$\circ$ TSP

(a)

(b)

FIgURE 4: Diagnostic PAH ratios for TSP samples collected at Mount Heng.

The air masses of N/NW group originated from the northern and northwestern China, where most industrial activities of China are located and burning of coal and biomass was the dominant energy source. So, particulate samples of this group had the highest PAHs concentrations, reaching $10.71 \mathrm{ng} / \mathrm{m}^{3}$. Unexpectedly, the group of L had higher PAHs concentrations than EA and S groups, and the average concentration reached $6.01 \mathrm{ng} / \mathrm{m}^{3}$. PHE was the predominant compound of L group, contributing over $20 \%$ of the total concentration. As presented in the study of Lin et al. [26], PHE is a major component of emissions from incense burning. There are several temples located in the Mount Heng region, and most of them are crowded with visitors. Therefore, incense burning inside or outside the temples is suggested to be an important local PAHs emission source. It should be noted that the relative fewer sample numbers of $L$ group could cause uncertainties to some degree. Air mass from eastern and southern China, the two most developed areas in China, had lower PAHs concentrations, which are 4.23 and $4.29 \mathrm{ng} / \mathrm{m}^{3}$, respectively.

3.4. Diagnostic Ratios of PAH. As suggested in prior studies, the concentrations and ratios of some tracer PAHs could be used to identify the contribution of different sources. Four common diagnostic ratios including FLA/(PYR + FLA), $\mathrm{IcdP} /(\mathrm{BghiP}+\mathrm{IcdP}), \mathrm{ANT} /(\mathrm{PHE}+\mathrm{ANT})$, and $\mathrm{BaA} /(\mathrm{BaA}+$ $\mathrm{CHR})$ were used to analyze the PAHs in particulate samples, and the results are presented in Figure 4.

According to the study of Yunker et al. [27], the ratio of FLA/(PYR + FLA) lower than 0.4 implies the unburned petrogenic sources and the ratio higher than 0.5 signals the coal and wood combustion, and a ratio between 0.4 and 0.5 indicates the liquid fossil fuel combustion sources. In this study, the ratio was 0.56 for particulate sample, indicating wood and coal combustion was the main source.
For IcdP/(BghiP + IcdP $)$, the ratio lower than 0.2 suggests unburned petrogenic sources, the ratio between 0.2 and 0.4 indicates liquid fossil fuel combustion sources, and the ratio higher than 0.5 signals the contribution of coal or wood combustion [6]. The ratio value was 0.38 for the sample, indicating comprehensive contributions from coal and liquid fossil fuel combustion sources. For another common used indicator $\mathrm{ANT} /(\mathrm{PHE}+\mathrm{ANT})$, a ratio lower than 0.1 signals the liquid fossil fuel sources and a ratio higher than 0.1 indicates the combustion sources. As presented in Figure 4, the ratios were all above 0.1 for particulate samples, indicating the combustion source contributions. In previous study, the ratio of $\mathrm{BaA} /(\mathrm{BaA}+\mathrm{CHR})$ higher than 0.35 indicates the coal or other biomass combustion sources, while the ratio lower than 0.2 signals the liquid fossil fuel sources [28]. In this study, the ratio was 0.29 for particulate sample, indicating the coal and liquid fossil fuel combustion contribution.

Based on the results of diagnostic ratios analysis, coal combustion and emissions from liquid fossil fuel consumption were suggested to be the dominating sources of particulate-bound PAHs at Mount Heng site. In our previous studies conducted at Mount Tai, the highest mountain in northern China, coal combustion and vehicular emissions were the main sources of PAHs in atmospheric samples as well $[1,2]$. The results obtained from the high altitude background sites could reflect an overall picture of $\mathrm{PAH}$ possible sources in China. However, special caution should be given when using diagnostic ratios. The ratio values could be altered as PAHs can react with other atmospheric compounds, such as hydroxyl radicals and/or ozone $[29,30]$. In addition, degradation during the transport can modify the concentrations and ratios of PAHs, which is another limitation of using diagnostic ratios [31]. For example, BaA and ANT have been proved to degrade more quickly than their isomers-CHR and $\mathrm{PHE}$, respectively $[32,33]$. 
TABLE 5: Factor analysis for particulate-bound PAHs.

\begin{tabular}{lcc}
\hline PAHs & Factor 1 & Factor 2 \\
\hline ACY & & 0.735 \\
ACE & & 0.977 \\
FLU & & 0.962 \\
PHE & & 0.790 \\
ANT & 0.857 & 0.846 \\
FLA & 0.882 & \\
PYR & 0.940 & \\
BaA & 0.922 & \\
CHR & 0.954 & \\
BbF & 0.709 & \\
BkF & 0.810 & \\
BaP & 0.851 & \\
IcdP & 0.895 & \\
DahA & 0.833 & \\
BghiP & 70.77 & Unburned fossil fuels \\
\% of variance & Vehicular and coal & and incense burning \\
Sources & combustion emission & \\
\hline
\end{tabular}

3.5. Factor Analysis. As stated above, several constraints exist when using diagnostic ratios to identify PAHs sources. Factor analysis, which served as an exploratory tool, can be used to quantify the major sources of PAHs. In this present study, the total concentrations of 15 PAHs compounds detected in particulate samples were subjected to factor analysis using SPSS version 16 (SPSS Inc.). Factor analysis was conducted with Varimax rotation, and factors with eigenvalue $>1$ were considered. The results of rotated factors are listed in Table 5.

Two factors were separated, accounting for $86.2 \%$ of the total variance in the data. Factor 1 , which explained $70.77 \%$ of the variance, presented high loading for individual PAHs with higher molecular weight, including FLA, PYR, BaA, CHR, $\mathrm{BbF}, \mathrm{BkF}, \mathrm{BaP}$, IcdP, DahA, and BghiP. According to previous studies, BbF, BkF, IcdP, and BghiP are the major components of vehicular emission, and the presence of FLA, PYR, BaA, and CHR could point to coal and wood combustion sources $[1,34,35]$. Thus, factor 1 could represent sources from vehicular and coal combustion emission. Factor 2, which explained $15.43 \%$ of the variance, is highly loaded on ACY, ACE, FLU, PHE, and ANT. ACY and ACE could signal the contribution of unburned fossil fuels. PHE and ANT have been identified in industry emission in previous studies $[1,6]$. PHE is also a major component of emissions from incense burning [26], while Flu could originate from different sources.

Based on the results of factor analysis, vehicular emission, coal combustion, industry emission, and unburned fossil fuels were suggested to be the PAHs sources at Mount Heng site. However, as mentioned earlier, the reactivity and degradation of individual PAHs could influence the results for profiles of PAH sources, and thus much work still needs to be conducted in the future.

\section{Conclusion}

Particulate-bound PAHs concentrations were investigated at high mountain region in Southern China from April to May 2009. The PAH concentrations ranged from 1.63 to $29.83 \mathrm{ng} / \mathrm{m}^{3}$, with a mean concentration of $6.03 \mathrm{ng} / \mathrm{m}^{3}$. The meteorological parameters including atmospheric pressure, relative humidity, and ambient temperature had good correlations with individual PAHs. The results obtained from air mass back trajectories and PAHs concentrations highlighted the importance of air mass origin. The air masses of $\mathrm{N} / \mathrm{NW}$ group, transported over the most polluted region of China, had relatively higher PAH concentrations. Both the diagnostic ratio and factor analysis suggested that vehicular emission, coal combustion, industry emission, and unburned fossil fuels were the possible sources of PAHs at Mount Heng site.

\section{Conflict of Interests}

The authors declare that there is no conflict of interests regarding the publication of this paper.

\section{Acknowledgments}

The authors are grateful to Mount Heng Meteorological Station for providing meteorological data and other support in the field observation. They thank Jinan Institute of Environmental Protection for the support of sample analysis. They appreciate the assistance from Zaifeng Wang, Houyong Zhang, Likun Xue, Xiaomei Gao, Wei Nie, and Shengzhen Zhou. This study was supported by the National Natural Science Foundation of China (21177073, 41475115), Tianjin 131 creative talents project, and Tianjin High School Science \& Technology Fund Planning Project (20140515).

\section{References}

[1] P.-H. Li, Y. Wang, Y.-H. Li et al., "Characterization of polycyclic aromatic hydrocarbons deposition in PM2.5 and cloud/fog water at Mount Taishan (China)," Atmospheric Environment, vol. 44, no. 16, pp. 1996-2003, 2010.

[2] Y. Wang, P.-H. Li, H.-L. Li, X.-H. Liu, and W.-X. Wang, "PAHs distribution in precipitation at Mount Taishan. China. Identification of sources and meteorological influences," Atmospheric Research, vol. 95, no. 1, pp. 1-7, 2010.

[3] S. S. Park, Y. J. Kim, and C. H. Kang, "Atmospheric polycyclic aromatic hydrocarbons in Seoul, Korea," Atmospheric Environment, vol. 36, no. 17, pp. 2917-2924, 2002.

[4] C. Vasilakos, N. Levi, T. Maggos, J. Hatzianestis, J. Michopoulos, and C. Helmis, "Gas-particle concentration and characterization of sources of PAHs in the atmosphere of a suburban area in Athens, Greece," Journal of Hazardous Materials, vol. 140, no. 1-2, pp. 45-51, 2007.

[5] S. Xu, W. Liu, and S. Tao, "Emission of polycyclic aromatic hydrocarbons in China," Environmental Science and Technology, vol. 40, no. 3, pp. 702-708, 2006.

[6] K. Ravindra, R. Sokhi, and R. van Grieken, "Atmospheric polycyclic aromatic hydrocarbons: source attribution, emission 
factors and regulation," Atmospheric Environment, vol. 42, no. 13, pp. 2895-2921, 2008.

[7] P.-H. Li, S.-F. Kong, C.-M. Geng et al., "Health risk assessment for vehicle inspection workers exposed to airborne polycyclic aromatic hydrocarbons (PAHs) in their work place," Environmental Sciences: Processes and Impacts, vol. 15, no. 3, pp. 623632, 2013.

[8] J. He and R. Balasubramanian, "Semi-volatile organic compounds (SVOCs) in ambient air and rainwater in a tropical environment: concentrations and temporal and seasonal trends," Chemosphere, vol. 78, no. 6, pp. 742-751, 2010.

[9] M. F. Simcik, T. P. Franz, H. Zhang, and S. J. Eisenreich, "Gas-particle partitioning of PCBs and PAHs in the Chicago urban and adjacent coastal atmosphere: states of equilibrium," Environmental Science and Technology, vol. 32, no. 2, pp. 251257, 1998

[10] M. À. Olivella, "Polycyclic aromatic hydrocarbons in rainwater and surface waters of Lake Maggiore, a subalpine lake in Northern Italy," Chemosphere, vol. 63, no. 1, pp. 116-131, 2006.

[11] J. He and R. Balasubramanian, "A study of precipitation scavenging of semivolatile organic compounds in a tropical area," Journal of Geophysical Research D: Atmospheres, vol. 114, no. 12, Article ID D12201, 2009.

[12] G. L. Daly and F. Wania, "Organic contaminants in mountains," Environmental Science and Technology, vol. 39, no. 2, pp. 385398, 2005.

[13] B. L. van Drooge, J. O. Grimalt, C. J. Torres García, and E. Cuevas, "Semivolatile organochlorine compounds in the free troposphere of the Northeastern Atlantic," Environmental Science and Technology, vol. 36, no. 6, pp. 1155-1161, 2002.

[14] W. Wang, S. L. M. Simonich, W. Wang et al., "Atmospheric polycyclic aromatic hydrocarbon concentrations and gas/particle partitioning at background, rural village and urban sites in the North China Plain," Atmospheric Research, vol. 99, no. 2, pp. 197-206, 2011.

[15] Y. Yang, P. Guo, Q. Zhang, D. Li, L. Zhao, and D. Mu, "Seasonal variation, sources and gas/particle partitioning of polycyclic aromatic hydrocarbons in Guangzhou, China," Science of the Total Environment, vol. 408, no. 12, pp. 2492-2500, 2010.

[16] S. Liu, S. Tao, W. Liu et al., "Atmospheric polycyclic aromatic hydrocarbons in north China: a winter-time study," Environmental Science and Technology, vol. 41, no. 24, pp. 8256-8261, 2007.

[17] H.-R. Cheng, G. Zhang, X. Liu, J. Li, S.-H. Qi, and Y.-C. Zhao, "Studies on polycyclic aromatic hydrocarbons in the atmosphere of Waliguan, Qinghai," China Environmental Science, vol. 26, no. 6, pp. 646-649, 2006.

[18] P. Fernández, J. O. Grimalt, and R. M. Vilanova, "Atmospheric gas-particle partitioning of polycyclic aromatic hydrocarbons in high mountain regions of Europe," Environmental Science \& Technology, vol. 36, no. 6, pp. 1162-1168, 2002.

[19] T. Primbs, A. Piekarz, G. Wilson et al., "Influence of Asian and Western United States urban areas and fires on the atmospheric transport of polycyclic aromatic hydrocarbons, polychlorinated biphenyls, and fluorotelomer alcohols in the Western United States," Environmental Science and Technology, vol. 42, no. 17, pp. 6385-6391, 2008.

[20] X. Ding, X. M. Wang, Z. Q. Xie et al., "Atmospheric polycyclic aromatic hydrocarbons observed over the North Pacific Ocean and the Arctic area: Spatial distribution and source identification," Atmospheric Environment, vol. 41, no. 10, pp. 2061-2072, 2007.
[21] F. Tian, J. Chen, X. Qiao et al., "Sources and seasonal variation of atmospheric polycyclic aromatic hydrocarbons in Dalian, China: factor analysis with non-negative constraints combined with local source fingerprints," Atmospheric Environment, vol. 43, no. 17, pp. 2747-2753, 2009.

[22] K. Ravindra, L. Bencs, E. Wauters et al., "Seasonal and sitespecific variation in vapour and aerosol phase PAHs over Flanders (Belgium) and their relation with anthropogenic activities," Atmospheric Environment, vol. 40, no. 4, pp. 771-785, 2006.

[23] A. Motelay-Massei, D. Ollivon, B. Garban, and M. Chevreuil, "Polycyclic aromatic hydrocarbons in bulk deposition at a suburban site: assessment by principal component analysis of the influence of meteorological parameters," Atmospheric Environment, vol. 37, no. 22, pp. 3135-3146, 2003.

[24] M. Tsapakis and E. G. Stephanou, "Occurrence of gaseous and particulate polycyclic aromatic hydrocarbons in the urban atmosphere: study of sources and ambient temperature effect on the gas/particle concentration and distribution," Environmental Pollution, vol. 133, no. 1, pp. 147-156, 2005.

[25] A. Li, J.-K. Jang, and P. A. Scheff, "Application of EPA CMB8.2 model for source apportionment of sediment PAHS in Lake Calumet, Chicago," Environmental Science and Technology, vol. 37, no. 13, pp. 2958-2965, 2003.

[26] T.-C. Lin, F.-H. Chang, J.-H. Hsieh, H.-R. Chao, and M.-R. Chao, "Characteristics of polycyclic aromatic hydrocarbons and total suspended particulate in indoor and outdoor atmosphere of a Taiwanese temple," Journal of Hazardous Materials, vol. 95, no. 1-2, pp. 1-12, 2002.

[27] M. B. Yunker, R. W. Macdonald, R. Vingarzan, R. H. Mitchell, D. Goyette, and S. Sylvestre, "PAHs in the Fraser River basin: a critical appraisal of PAH ratios as indicators of PAH source and composition," Organic Geochemistry, vol. 33, no. 4, pp. 489-515, 2002.

[28] H. H. Soclo, P. Garrigues, and M. Ewald, "Origin of polycyclic aromatic hydrocarbons (PAHs) in coastal marine sediments: case studies in Cotonou (Benin) and Aquitaine (France) Areas," Marine Pollution Bulletin, vol. 40, no. 5, pp. 387-396, 2000.

[29] A. L. Robinson, R. Subramanian, N. M. Donahue, A. BernardoBricker, and W. F. Rogge, "Source apportionment of molecular markers and organic aerosol-1. Polycyclic aromatic hydrocarbons and methodology for data visualization," Environmental Science and Technology, vol. 40, no. 24, pp. 7803-7810, 2006.

[30] A. L. Robinson, N. M. Donahue, and W. F. Rogge, "Photochemical oxidation and changes in molecular composition of organic aerosol in the regional context," Journal of Geophysical Research D: Atmospheres, vol. 111, no. 3, Article ID D03302, 2006.

[31] M. Tsapakis and E. G. Stephanou, "Collection of gas and particle semi-volatile organic compounds: use of an oxidant denuder to minimize polycyclic aromatic hydrocarbons degradation during high-volume air sampling," Atmospheric Environment, vol. 37, no. 35, pp. 4935-4944, 2003.

[32] R. M. Kamens, Z. Guo, J. N. Fulcher, and D. A. Bell, "Influence of humidity, sunlight, and temperature on the daytime decay of polyaromatic hydrocarbons on atmospheric soot particles," Environmental Science and Technology, vol. 22, no. 1, pp. 103108, 1988.

[33] J. J. Schauer, W. F. Rogge, L. M. Hildemann, M. A. Mazurek, G. R. Cass, and B. R. T. Simoneit, "Source apportionment of airborne particulate matter using organic compounds as tracers," Atmospheric Environment, vol. 30, no. 22, pp. 38373855, 1996. 
[34] H. Guo, S. C. Lee, K. F. Ho, X. M. Wang, and S. C. Zou, "Particleassociated polycyclic aromatic hydrocarbons in urban air of Hong Kong," Atmospheric Environment, vol. 37, no. 38, pp. 53075317, 2003.

[35] W. Zhang, S. Zhang, C. Wan, D. Yue, Y. Ye, and X. Wang, "Source diagnostics of polycyclic aromatic hydrocarbons in urban road runoff, dust, rain and canopy throughfall," Environmental Pollution, vol. 153, no. 3, pp. 594-601, 2008.

[36] J. Zhou, Y. Wang, T. X. Yue, Y. H. Li, K.-M. Wai, and W. X. Wang, "Origin and distribution of trace elements in high-elevation precipitation in Southern China," Environmental Science and Pollution Research, vol. 19, no. 8, pp. 3389-3399, 2012. 

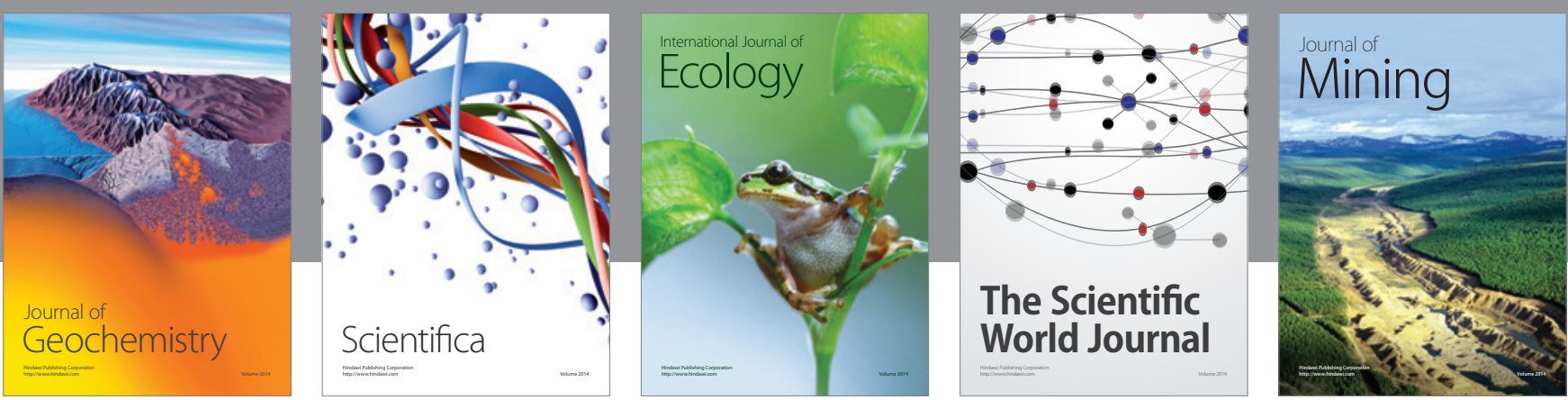

The Scientific World Journal
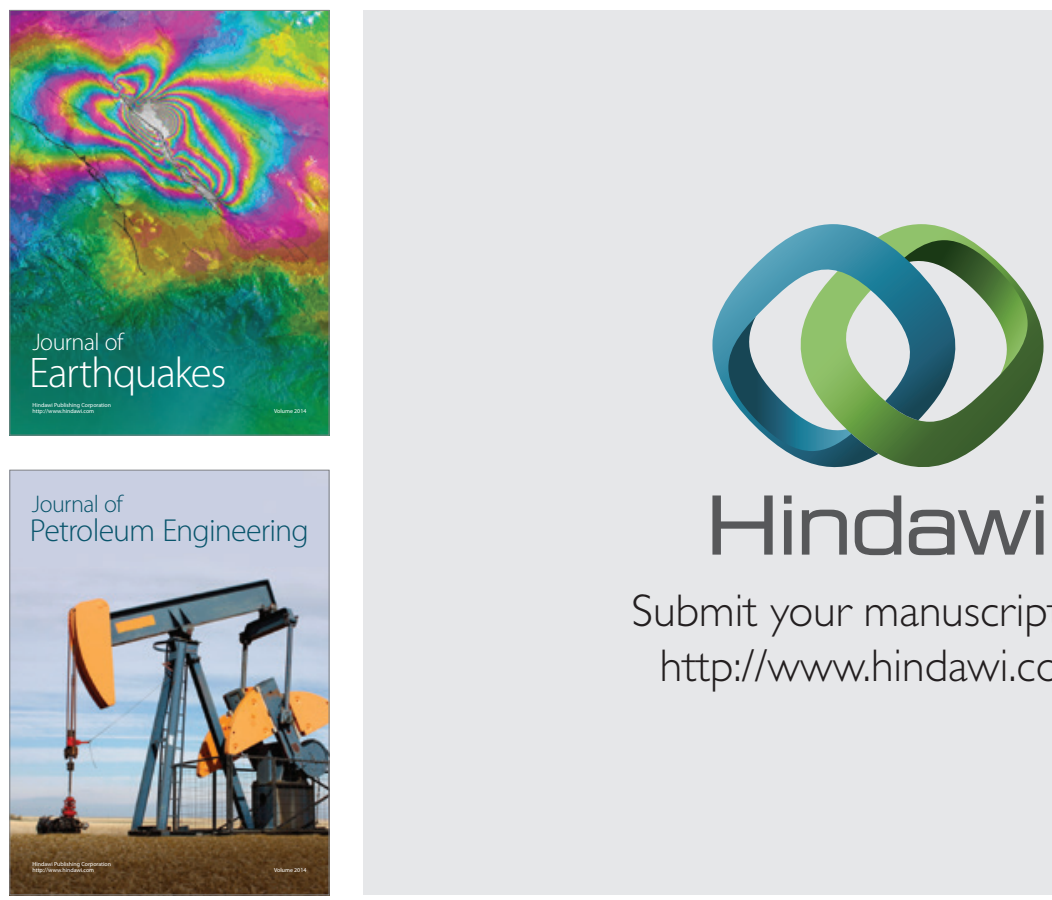

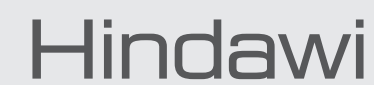

Submit your manuscripts at

http://www.hindawi.com
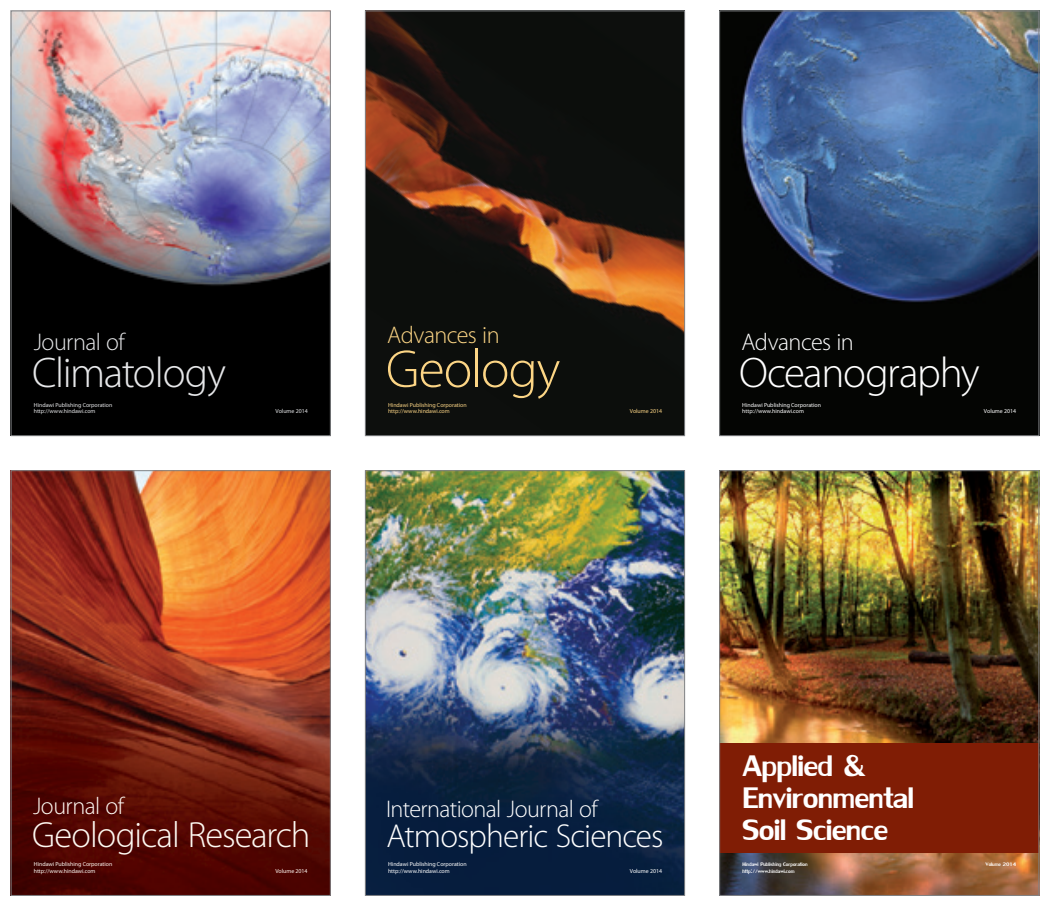
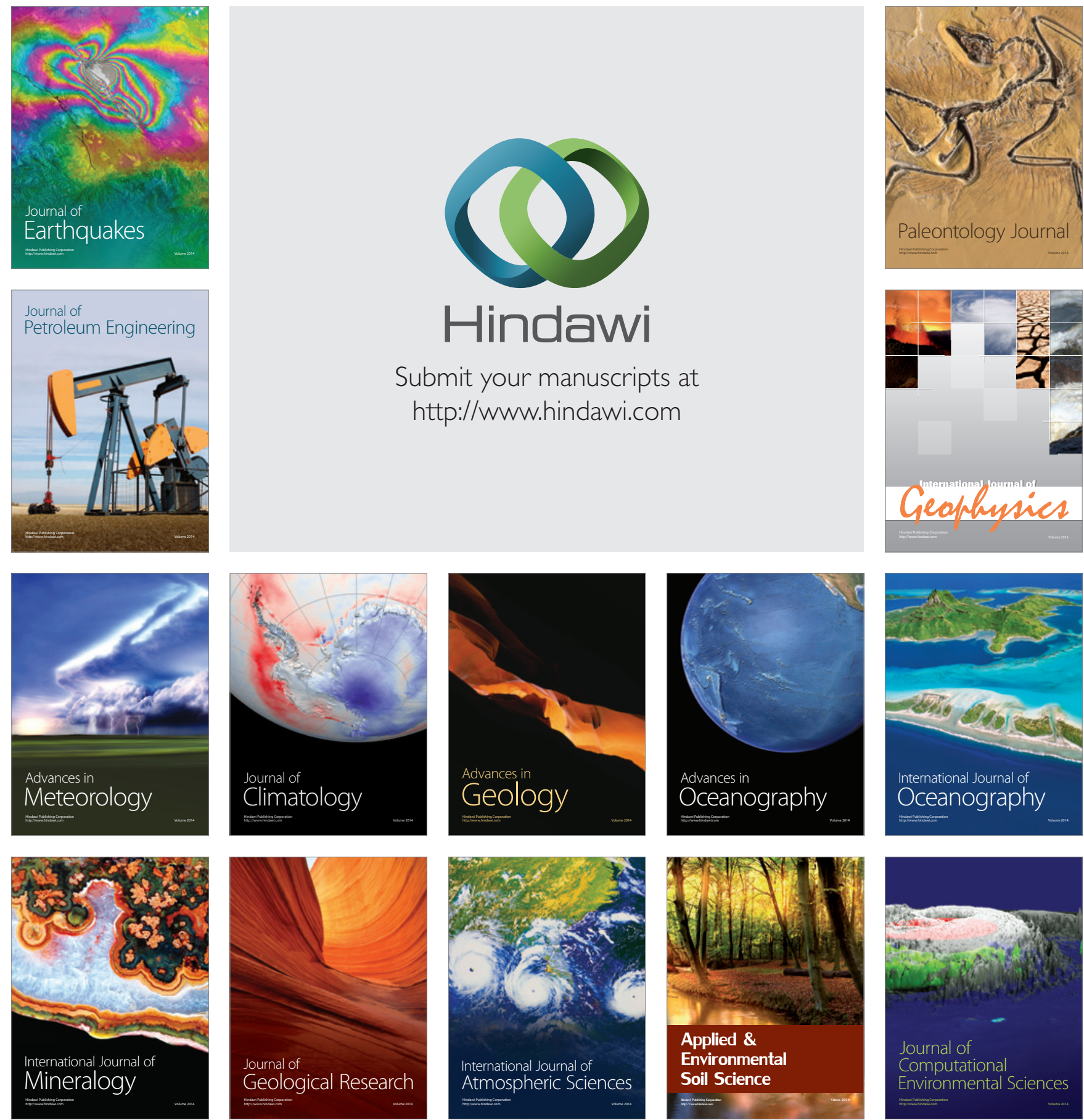